\title{
Domestic Violence against Women during Pregnancy: The Case of Palestinian Refugees Attending an Antenatal Clinic in Lebanon
}

\author{
N. Hammoury, M.S., ${ }^{1}$ M. Khawaja, Ph.D., ${ }^{1,2}$ Z. Mahfoud, Ph.D., ${ }^{1}$ R.A. Afifi, Ph.D., ${ }^{3}$ and H. Madi, M.D. ${ }^{4}$
}

\begin{abstract}
Objectives: To determine the factors associated with domestic violence against pregnant Palestinian refugee women residing in Lebanon and currently using the United Nation Relief and Work Agency's (UNRWA) primary healthcare services.

Methods: This was a cross-sectional study conducted at a polyclinic of primary healthcare of the UNRWA in South Lebanon during the years 2005-2006. The sample was 351 pregnant women who were 15-42 years of age and not accompanied by their husbands or relatives. All women were invited by the midwife to participate in the study during their visit to the clinic for their first checkup or during a follow-up visit. The Abuse Assessment Screen instrument was used to screen for past and recent history of physical and emotional abuse among the participants.

Results: Domestic violence was significantly associated with education, gestational age, fear of husband or someone else in the house, and unintended pregnancy. The odds of abuse for women with an elementary or lower education were 6.86 (95\% CI 1.2-38.1) and for women with an intermediate or secondary education 6.84 (95\% CI 1.4-33.3) compared with women with a university education. The odds of abuse during pregnancy for women whose husbands did not desire their pregnancy were 3.80 (95\% CI 1.5-9.7) compared with other women. Conclusions: Domestic violence against women in Lebanon was associated with educational level, gestational age, fear of husband or someone else in the house, and unintended pregnancy.
\end{abstract}

\section{Introduction}

D OMESTIC VIOLENCE (DV) against women is a significant public health issue in both developed and developing countries of the world. ${ }^{1-3}$ According to the World Health Organization (WHO), surveys from around the world indicate that approximately $10 \%-69 \%$ of women report being physically assaulted by an intimate male partner at some point in their lives. ${ }^{4} \mathrm{DV}$ is also considered a violation of human rights and has, therefore, received increased global attention by international organizations and human rights committees during the past two decades. In 1981, the United Nations Committee on the Elimination of Discrimination against Women (CEDAW) affirmed a policy of eliminating any discrimination on the basis of sex that would affect an individual's human rights and fundamental freedoms. ${ }^{3}$ In 1993, The World Conference on Human Rights in Vienna declared that violence against women entails a severe violation of rights. ${ }^{3}$
Pregnancy does not protect women from violence. ${ }^{5}$ This is reflected by the alarming prevalence rates of physical abuse found in the prepregnancy, antepartum, and postpartum periods, demonstrating that all women of reproductive age are at risk for intimate partner violence (IPV). ${ }^{5-8}$ A study reports that the prevalence of IPV in the prepregnancy period reaches $23 \%-25 \%$ but increases to $52 \%$ during pregnancy. ${ }^{9}$ Studies conducted in developing nations report that between $4 \%$ and $29 \%$ of all women are abused during pregnancy. ${ }^{10-12}$

A growing body of evidence has linked domestic violence against women to a range of adverse reproductive health outcomes, including nonuse of contraception and unwanted pregnancy, ${ }^{10,13-20}$ as well as obstetric complications and depressive symptomatology. ${ }^{19,21-22}$

Despite its increasing global importance, there has been little research on DV against women in the Arab region. ${ }^{1,11,23-25}$ A few studies investigated the prevalence of DV and its impacts on health and morbidity in refugee populations ${ }^{1}$ or in

\footnotetext{
${ }^{1}$ Department of Epidemiology and Population Health, ${ }^{2}$ Center for Research on Population and Health, and ${ }^{3}$ Department of Health Behavior and Education, American University of Beirut, Beirut, Lebanon.

${ }^{4}$ Department of Health, UNRWA Headquarter, Amman, Jordan.
} 
the Arab family. ${ }^{23,25}$ Studies conducted in neighboring settings (Egypt, Palestine, Tunisia, and Israel) indicated that at least one of three women is beaten by her husband. ${ }^{2}$ A previous study on DV against women from poor refugee communities in Lebanon found that $29.5 \%$ of husbands and $22 \%$ of their wives reported that wife-beating occurred at least once during their marriage. ${ }^{26}$ The prevalence of wife-beating in Jordanian refugee camps during a woman's lifetime was $44.7 \%{ }^{27}$ Preliminary descriptive findings from this screening study revealed that DV against pregnant refugee women was common, $59 \%$ women had ever experienced physical violence, $19.1 \%$ experienced physical violence during the past year, $26.2 \%$ were subjected to sexual coercion, $16.8 \%$ experienced emotional violence, and $11.4 \%$ experienced physical violence during pregnancy. ${ }^{28}$ To our knowledge, no study has been conducted to investigate the factors associated with DV against women during pregnancy in the Arab region.

Violence against women is a complex problem that cannot be attributed to a single cause but to a diverse set of factors, including demographic, ${ }^{4,9,29,30}$ socioeconomic, ${ }^{4,9,29-30}$ and cultural ones. ${ }^{4,931-32}$ The link between DV against women generally and specifically during pregnancy has been established, and previous research indicates that many of the same factors are salient.

This study aims to investigate common factors associated with DV among pregnant Palestinian refugee women currently using the United Nation Relief Work Agency's (UNRWA) primary healthcare services in Lebanon. Pregnancy provides a unique opportunity to routinely ask screening questions on DV against women, 9,13,15 as it is a period when women tend to take greater interest in and responsibility for their own health and have more contact with health professionals.

It is important to consider the context of the study. For nearly 60 years, Palestinian refugees in Lebanon have been living under precarious conditions characterized by economic hardship, patriarchy, and future uncertainty. Conditions in the camps are harsh, and despite large improvements in health and education, camp residents continue to experience relatively high levels of extreme poverty, war-related disabilities, and poor living conditions. They are largely isolated from the rest of Lebanese society; denied participation in national health care, education, and social service programs; and have little access to the formal labor market. The dire living conditions facing women in this unusual context are likely to have a direct bearing on DV, particularly IPV.

\section{Materials and Methods}

The research design was cross-sectional and quantitative in nature. The sample was obtained from the polyclinic of the UNRWA in Sidon, South of Lebanon, during a 1-month period (June 14 to July 14, 2005). UNRWA provides primary healthcare to refugees through its 25 primary healthcare facilities in Lebanon and is the main provider of prenatal care in both refugee camps and other communities of registered $\mathrm{Pa}-$ lestinian refugees there. The setting of this study is located in the middle of the Lebanese city of Sidon. Only Palestinian refugees are allowed to benefit from the provided services.

A cross-sectional survey was used to collect data from pregnant women attending the antenatal healthcare clinic. The first author, who is a trained midwife specialist, invited all women to participate in the study during the women's visits to the healthcare center for their first checkup or during a follow-up visit. Women were approached to participate in the study while waiting to see a doctor or a nurse/midwife specialist. For ethical reasons, including potential retaliation from disclosure, women were interviewed in private. Women who were accompanied by their husbands were not interviewed during the first visits but were asked to participate in the study during subsequent visits when they were alone. Data on demographic and socioeconomic factors were retrieved from clinic health records. All respondents were informed of the objective of the study, and informed consent was obtained verbally prior to interviewing. The study followed WHO ethical guidelines, with particular attention to privacy and safety, ${ }^{33}$ and the study protocol was reviewed and approved by a local ethics committee.

Three hundred fifty-one pregnant women were recruited into this study. Only 2 pregnant women did not take part. One of them considered the problem a private matter that should not be discussed outside the family. The other one broke down in tears when approached to participate, and the midwife stopped the interview. The remaining 349 women completed the interview (response rate 99.4\%).

The instrument used to measure abuse was derived from the widely used Abuse Assessment Screen (AAS). ${ }^{19}$ The AAS was developed by Parker, Ulrich, and the Nursing Research Consortium on Violence and Abuse (1990). ${ }^{34}$ The AAS is a well-validated screening tool used to initially identify and continually assess for IPV and has been used elsewhere as a confidential screening tool. The AAS tool is a 5-item questionnaire with Yes or No options; it takes 45 seconds to complete if all the answers are negative. Any positive answer is considered a woman subjected to abuse. The 5 items include questions on physical, emotional, and sexual violence during three periods: marital lifetime (ever beaten), last year, and current pregnancy. A recent validation study found that using four questions from the AAS instrument successfully identified women experiencing violence in the past year when compared with the 30-item Composite Abuse Scale. ${ }^{35}$ The AAS was translated into spoken Arabic, the language of both the respondents and the interviewer. Literal translation of the instrument may reduce its content validity ${ }^{36}$ and was, therefore, avoided. A pilot study with 11 pregnant women in similar settings was carried out 1 month before implementation of the main study to assess the Arabic version of the instrument in the target population. The results of the pilot showed that participants were able to answer the questions in the Arabic version of the instrument, and only minor wording changes were needed before fielding the main study.

The outcome variables were women's experience with DV during her lifetime, past year, and current pregnancy. Ever beaten was measured using the following question (1) in the AAS instrument: Have you ever been emotionally or physically abused by your husband or someone related to you? Violence during last year was assessed using the question (2 in AAS): Within the last year, have you been hit, slapped, kicked, or otherwise physically hurt by your husband or someone else? Violence during current pregnancy was captured by using the following question ( 3 in AAS): Since your pregnancy began, have you been hit, slapped, kicked, or otherwise physically hurt by your husband or someone else? The three dependent items were coded into a binary measure $(1=$ yes, abused, and $2=$ no, not abused). 
Possible factors associated with DV during pregnancy included a variety of sociodemographic items, such as the respondents' completed education (elementary level or less, intermediate and secondary level, university level), employment status of the husband and the women $(1=$ yes or $2=$ no), area of residence (refugee camp vs. noncamp area), and age of women (15-24, 25-29, 30-34, $\geq 35$ years). Other variables of interest comprised reproductive health-related factors, such as the number of deliveries (parity: coded into primipara or multipara), duration of marriage ( $\leq 1$ year or $>1$ year), gestational weeks at the time of screening classified as (first trimester, second trimester, or third trimester), and desiredness of pregnancy by either the husband or the wife measured using the following questions: Did you desire this pregnancy? Did your husband desire this pregnancy? These were coded into a binary measure $(1=$ yes, desired this pregnancy, or $2=$ no, not desired).

A final variable indicating fear of husband or someone else in the house was measured by the question (4 in the AAS instrument): Are you afraid of your husband or anyone else in this house? The answer was $1=$ yes, afraid; $2=$ no, not afraid.

The software program SPSS 13.0 for Windows was used for the analysis (SPSS, Chicago, IL). The data were analyzed using descriptive statistics, chi-square test of associations, and logistic regressions. Various interactions between exposure variables were examined to explore possible effects, but none were statistically significant. The multivariate regression models included all relevant variables regardless of their statistical significance at the bivariate level.

\section{Results}

As shown in Table 1, the age of the women who participated in the research ranged from 15 to 42 years (mean 27.9 years), and the average educational level of the total sample was 9.3 years. Only about $10 \%(9.7 \%)$ of the participants were employed, compared with $94.4 \%$ of their husbands at the time of the survey. Seventy-one percent of pregnant women resided outside the camp; this reflects the location of the polyclinic. Most of the pregnant women were multipara $(52.1 \%)$, and $41.3 \%$ were in their second trimester of pregnancy. Average age at marriage was 21 years, and 39\% of women were married before the age of 20 years. Seventy-five percent of the respondents were married for $>1$ year, and $68.1 \%$ of them desired their pregnancy at the time of the survey compared with $84 \%$ of their husbands. Sixteen percent of the respondents reported being afraid of their husband or someone else in the house.

Two hundred seven participants (59\%) reported having been abused at any time during their married life, 67 (19.1\%) who were abused during the last 12 months and 40 who were abused $(11.4 \%)$ during the current pregnancy. ${ }^{27}$ The mean age of women who had ever been emotionally or physically abused was 28 years, which was slightly higher than those who were abused within the last year (26.25 years) or during pregnancy (25.5 years). Women who had been abused also had a lower level of education on average than the general sample: 8.5 years for those who were subjected to abuse during their lifetime and 7.4 years for those who were abused during pregnancy and last year. Similar to the general sample, about half of pregnant women who were abused during the
Table 1. Frequency Distribution of Variables FOR DOMESTIC ViOLENCE

\begin{tabular}{|c|c|c|}
\hline Variable & No. & $\%$ \\
\hline \multicolumn{3}{|c|}{ Emotionally or physically abused (lifetime) } \\
\hline Yes & 207 & 59.0 \\
\hline No & 142 & 40.5 \\
\hline \multicolumn{3}{|l|}{ Physically abused (last year) } \\
\hline Yes & 67 & 19.1 \\
\hline No & 282 & 80.3 \\
\hline \multicolumn{3}{|c|}{ Physically abused (during pregnancy) } \\
\hline Yes & 40 & 11.4 \\
\hline No & 309 & 88.0 \\
\hline \multicolumn{3}{|l|}{ Educational level } \\
\hline Elementary or less & 64 & 18.2 \\
\hline Intermediate and secondary & 202 & 57.5 \\
\hline University & 85 & 24.2 \\
\hline \multicolumn{3}{|l|}{ Employment of respondent } \\
\hline No & 315 & 89.7 \\
\hline Yes & 34 & 9.7 \\
\hline \multicolumn{3}{|l|}{ Employment of husband } \\
\hline No & 18 & 5.1 \\
\hline Yes & 333 & 94.9 \\
\hline \multicolumn{3}{|l|}{ Place of residence } \\
\hline Inside camp & 101 & 28.8 \\
\hline Outside camp & 249 & 70.9 \\
\hline \multicolumn{3}{|c|}{ Fear of husband or someone else in the house } \\
\hline Yes & 56 & 16.0 \\
\hline No & 292 & 83.2 \\
\hline \multicolumn{3}{|l|}{ Age, years } \\
\hline $15-24$ & 119 & 33.9 \\
\hline $25-29$ & 96 & 27.4 \\
\hline $30-34$ & 65 & 18.5 \\
\hline $35+$ & 69 & 19.7 \\
\hline \multicolumn{3}{|l|}{ Parity } \\
\hline Primipara & 167 & 47.7 \\
\hline Multipara & 183 & 52.1 \\
\hline \multicolumn{3}{|l|}{ Length of marriage, years } \\
\hline$\leq 1$ & 85 & 24.2 \\
\hline$>1$ & 264 & 75.2 \\
\hline \multicolumn{3}{|l|}{ Gestational age } \\
\hline First trimester & 89 & 25.4 \\
\hline Second trimester & 145 & 41.3 \\
\hline Third trimester & 115 & 32.8 \\
\hline \multicolumn{3}{|l|}{ Desired pregnancy (respondent) } \\
\hline No & 112 & 31.9 \\
\hline Yes & 239 & 68.1 \\
\hline \multicolumn{3}{|l|}{ Desired pregnancy (husband) } \\
\hline No & 56 & 16.0 \\
\hline Yes & 295 & 84.0 \\
\hline
\end{tabular}

current pregnancy were primipara (57.5\%) and in their second trimester of pregnancy (50\%). The average length of marriage of those who experienced violence during pregnancy was 4.8 years (data not shown).

Bivariate associations between DV against women and selected vulnerability factors are presented in Table 2. As judged by chi-square tests, educational status of women and being afraid of their husband or another person in the house were significantly associated $(p<0.01)$ with a history of violence at any point in the woman's life. These same variables were significantly related $(p<0.01)$ to exposure to violence in the past year. As for violence during pregnancy, the same variables $(p<0.01)$, in addition to the desiredness of the 
Table 2. Bivariate Associations between Domestic Violence against Women at Different Times by Vunerability Factors

\begin{tabular}{|c|c|c|c|c|c|c|c|c|c|}
\hline \multirow[b]{2}{*}{ Variable } & \multicolumn{3}{|c|}{ Lifetime } & \multicolumn{3}{|c|}{ Last year } & \multicolumn{3}{|c|}{ During pregnancy } \\
\hline & No. & $\%$ & $\mathrm{p}$ value $^{\mathrm{a}}$ & No. & $\%$ & $\mathrm{p}$ value $^{\mathrm{a}}$ & No. & $\%$ & $\mathrm{p}$ value $\mathrm{a}^{\mathrm{a}}$ \\
\hline \multicolumn{10}{|l|}{ Educational level } \\
\hline Elementary or less & 48 & 75.0 & \multirow[t]{3}{*}{0.00} & 17 & 26.6 & \multirow[t]{3}{*}{0.00} & 11 & 17.2 & \multirow[t]{3}{*}{0.01} \\
\hline Intermediate and secondary & 121 & 60.5 & & 47 & 23.5 & & 27 & 13.5 & \\
\hline University & 38 & 44.7 & & 3 & 3.5 & & 2 & 2.4 & \\
\hline \multicolumn{10}{|l|}{ Employment of respondent } \\
\hline Yes & 18 & 52.9 & \multirow{2}{*}{0.42} & 4 & 11.8 & \multirow{2}{*}{0.26} & 3 & 8.8 & \multirow[t]{2}{*}{0.64} \\
\hline No & 188 & 60.1 & & 62 & 19.8 & & 36 & 11.5 & \\
\hline \multicolumn{10}{|l|}{ Employment of husband } \\
\hline Yes & 196 & 59.2 & \multirow{2}{*}{0.87} & 62 & 18.7 & \multirow{2}{*}{0.34} & 37 & 11.2 & \multirow[t]{2}{*}{0.48} \\
\hline No & 11 & 61.1 & & 5 & 27.8 & & 3 & 16.7 & \\
\hline \multicolumn{10}{|l|}{ Place of residence } \\
\hline Inside camp & 65 & 64.4 & \multirow[t]{2}{*}{0.22} & 25 & 24.8 & \multirow[t]{2}{*}{0.09} & 16 & 15.8 & \multirow[t]{2}{*}{0.10} \\
\hline Outside camp & 142 & 57.3 & & 42 & 16.9 & & 24 & 9.7 & \\
\hline \multicolumn{10}{|c|}{ Fear of husband or someone else in house } \\
\hline Yes & 48 & 85.7 & \multirow[t]{2}{*}{0.00} & 21 & 37.5 & \multirow{2}{*}{0.00} & 13 & 23.2 & \multirow[t]{2}{*}{0.01} \\
\hline No & 158 & 54.1 & & 45 & 15.4 & & 27 & 9.2 & \\
\hline \multicolumn{10}{|l|}{ Age, years } \\
\hline $15-24$ & 67 & 56.3 & 0.88 & 29 & 24.4 & 0.16 & 20 & 16.8 & 0.07 \\
\hline $25-29$ & 58 & 60.4 & & 20 & 20.8 & & 11 & 11.5 & \\
\hline $30-34$ & 39 & 60.0 & & 10 & 15.4 & & 6 & 9.2 & \\
\hline $35+$ & 42 & 61.8 & & 8 & 11.8 & & 3 & 4.4 & \\
\hline Parity & & & & & & & & & \\
\hline Primipara & 91 & 54.5 & 0.08 & 36 & 21.6 & 0.28 & 23 & 13.8 & 0.13 \\
\hline Multipara & 116 & 63.7 & & 31 & 17.0 & & 17 & 9.3 & \\
\hline Length of marriage, years & & & & & & & & & \\
\hline$\leq 1$ & 44 & 51.8 & 0.11 & 14 & 16.5 & 0.45 & 9 & 10.6 & 0.76 \\
\hline$>1$ & 162 & 61.6 & & 53 & 20.2 & & 31 & 11.8 & \\
\hline Gestational age & & & & & & & & & \\
\hline First trimester & & & & & & & 4 & 4.5 & 0.06 \\
\hline Second trimester & & & & & & & 20 & 13.9 & \\
\hline Third trimester & & & & & & & 16 & 13.9 & \\
\hline Desired pregnancy (responden & & & & & & & & & \\
\hline Yes & & & & & & & 21 & 8.8 & 0.02 \\
\hline No & & & & & & & 19 & 17.1 & \\
\hline Desired pregnancy (husband) & & & & & & & & & \\
\hline Yes & & & & & & & 25 & 8.5 & 0.00 \\
\hline No & & & & & & & 15 & 26.8 & \\
\hline
\end{tabular}

${ }^{\mathrm{a}}$ Two-tailed $p$ value for chi-square test.

pregnancy $(p<0.02)$, were statistically significant. Employment of the respondents and employment of husbands, place of residence inside or outside camp, parity, and duration of marriage were not significantly associated with violence during lifetime, last year, or during pregnancy.

Table 3 shows the results of the adjusted logistic regression models. Educational level and being afraid remained significant factors for lifetime violence, adjusting for age, employment, length of marriage, place of residence, and parity. The odds of lifetime violence for women with elementary or less education were 2.91 (95\% CI 1.35-6.34) times more than the odds for women with university degrees. The odds of abuse for respondents who were afraid of their husband or someone else in the house were 5.05 (95\% CI 2.26-11.28) times more than the odds for other women.

Educational status and fear of husband or someone else in the house were also associated with violence during the past year. The odds of experiencing abuse during the past year for women who had an elementary educational level or less were 7.57 times (95\% CI 1.945-29.54) and for those with an intermediate and secondary level were 7.32 times (95\% CI 2.0725.84) greater than the odds for women with a university education. The odds of past year violence for women who were afraid of their husbands were 2.65 (95\% CI 1.34-5.25) times more than the odds for other women. The odds for length of marriage were also marginally significant at 0.43 (95\% CI 0.18-0.99) for women married for $\leq 1$ year compared with other women.

Results indicated that educational status, desiredness of pregnancy, and gestational age remained the main significant factors associated with DV during pregnancy, adjusting for all other variables. The logistic regression model indicated that the odds of abuse during pregnancy for women with an elementary educational level were 6.86 (95\% CI 1.24-38.07) times 
Table 3. Adjusted Odds Ratios (95\% Ci) from Logistic Regression of Variables Associated with Domestic Violence against Women at Different Times

\begin{tabular}{|c|c|c|c|c|c|c|}
\hline \multirow[b]{2}{*}{ Variable } & \multicolumn{2}{|c|}{ Lifetime } & \multicolumn{2}{|c|}{ Last year } & \multicolumn{2}{|c|}{ During pregnancy } \\
\hline & OR & $95 \% C I$ & $O R$ & $95 \% C I$ & OR & $95 \% C I$ \\
\hline \multicolumn{7}{|l|}{ Educational level } \\
\hline Elementary or less & 2.91 & $1.35-6.34$ & 7.57 & $1.94-29.54$ & 6.86 & $1.24-38.07$ \\
\hline Intermediate and secondary & 1.60 & $0.91-2.83$ & 7.32 & $2.07-25.84$ & 6.84 & $1.41-33.23$ \\
\hline University & 1.00 & & 1.00 & & 1.00 & \\
\hline \multicolumn{7}{|l|}{ Employment of respondent } \\
\hline Yes & 1.00 & & 1.00 & & 1.00 & \\
\hline No & 0.98 & $0.44-2.19$ & 0.77 & $0.23-2.60$ & 0.46 & $0.10-2.14$ \\
\hline \multicolumn{7}{|l|}{ Employment of husband } \\
\hline Yes & 1.00 & & 1.00 & & 1.00 & \\
\hline No & 1.02 & $0.36-2.86$ & 1.73 & $0.55-5.43$ & 1.60 & $0.37-6.90$ \\
\hline \multicolumn{7}{|l|}{ Place of residence } \\
\hline Inside camp & 1.11 & $0.66-1.87$ & 1.39 & $0.74-2.60$ & 1.69 & $0.75-3.80$ \\
\hline Outside camp & 1.00 & & 1.00 & & 1.00 & \\
\hline \multicolumn{7}{|c|}{ Fear of husband or someone else in house } \\
\hline Yes & 5.05 & $2.26-11.28$ & 2.65 & $1.34-5.25$ & 2.04 & $0.86-4.85$ \\
\hline No & 1.00 & & 1.00 & & 1.00 & \\
\hline \multicolumn{7}{|l|}{ Age, years } \\
\hline $15-24$ & 0.83 & $0.36-1.94$ & 1.59 & $0.54-4.68$ & 4.02 & $0.86-18.79$ \\
\hline $25-29$ & 1.01 & $0.48-2.11$ & 1.42 & $0.52-3.86$ & 2.39 & $0.53-10.67$ \\
\hline $30-34$ & 0.93 & $0.44-1.96$ & 1.12 & $0.39-3.23$ & 2.31 & $0.50-10.72$ \\
\hline $35+$ & 1.00 & & 1.00 & & 1.00 & \\
\hline \multicolumn{7}{|l|}{ Parity } \\
\hline Primipara & 0.82 & $0.43-1.59$ & 1.94 & $0.90-4.18$ & 2.59 & $0.95-7.04$ \\
\hline Multipara & 1.00 & & 1.00 & & 1.00 & \\
\hline \multicolumn{7}{|l|}{ Length of marriage, vears } \\
\hline$\leq 1$ & 0.85 & $0.43-1.68$ & 0.43 & $0.18-0.99$ & 0.38 & $0.13-1.11$ \\
\hline$>1$ & 1.00 & & 1.00 & & & \\
\hline \multicolumn{7}{|l|}{ Gestational age } \\
\hline First trimester & & & & & 1.00 & \\
\hline Second trimester & & & & & 3.30 & $1.00-10.88$ \\
\hline Third trimester & & & & & 4.02 & $1.17-13.80$ \\
\hline \multicolumn{7}{|l|}{ Desired pregnancy (respondent) } \\
\hline No & & & & & 1.59 & $0.66-3.83$ \\
\hline Yes & & & & & 1.00 & \\
\hline \multicolumn{7}{|l|}{ Desired pregnancy (husband) } \\
\hline No & & & & & 3.80 & $1.49-9.72$ \\
\hline Yes & & & & & 1.00 & \\
\hline
\end{tabular}

more and for women with intermediate or secondary level of education were 6.84 times $(95 \%$ CI $1.41-33.23)$ more than the odds for women with a university education. The odds of experiencing violence for women in their third trimester of gestational age were $4.02(95 \%$ CI 1.17-13.80) times more than those of women in their first trimester. The corresponding odds at the second trimester were only marginally significant at 3.30 (95\% CI 1.00-10.88). Finally, the odds of abuse during pregnancy for women whose husbands did not desire the pregnancy were 3.80 (95\% CI 1.49-9.72) times more than the odds for other women. Fear of husband or someone else in the house, age, employment, undesired pregnancy by women, and place of residence were not associated with violence during pregnancy in our sample.

\section{Discussion}

To our knowledge, this is the first study to assess possible factors associated with DV toward pregnant women in
Lebanon and other Arab countries. This study revealed a high prevalence of DV occurring during a woman's lifetime. To date in Arab countries, DV against women has not been considered a public health issue. ${ }^{2}$ Furthermore, Palestinian refugees in Lebanon have been considered non-citizen populations and have been largely excluded from participation in Lebanese society, with no access to governmental healthcare, making the study of DV and the needs of pregnant refugee women in this particular context of public concern.

Prevalence rates of abuse found in this study were generally high but are consistent with previous studies. The overall prevalence of DV in the world is between $10 \%$ and $69 \%{ }^{4}$ According to a WHO multicountry study, ${ }^{37}$ the prevalence of physical violence against women ranged from $12.9 \%$ in a Japanese city to $61 \%$ in a Peruvian province during lifetime and from $3.1 \%$ in a Japanese city to $29 \%$ in an Ethiopian province during the past year. The estimate of violence during pregnancy was similar to rates reported from China $(11.2 \%)^{17}$ and other estimates from developing countries, which ranged from 
$4 \%$ to $29 \%{ }^{10,12,38}$ The WHO multicountry study ${ }^{37}$ showed similar rates of violence during pregnancy, ranging from $1 \%$ in a Japanese city to $28 \%$ in a Peruvian province. The variation in the rates could be due to the definition of violence, research design, and screening instruments used in the studies. In addition, these instruments varied between settings, cultures, and populations. ${ }^{14,39}$ Although the WHO multicountry study ${ }^{37}$ used a standard instrument across settings and cultures, it asked ever pregnant women about any abuse during their previous pregnancies. Data from such retrospective questions could suffer from recall bias. There is evidence that the rate of DV toward women could be detected better with the use of a structured screening instrument during the current pregnancy, ${ }^{15,39-41}$ but the performance and effectiveness of the screening methods are difficult to compare across screening tools. $^{42}$

We found strong associations between educational level and DV. In both bivariate and multivariate analysis, educational level outweighed all other variables in its association with the three violence outcomes. Our results were that women who were less educated had higher odds of abuse during their lifetime, last year, and during pregnancy than more educated women. These results are in line with other previous studies. $7,10,13,19,24,25,30,31,42-46$ A study of Korean women examining their response to abuse indicated that more educated women had more power to manage their life and better opportunities to participate in supportive life activities outside the home than did less educated women. ${ }^{47}$ However, the association between educational level and DV was not significant in some studies conducted in Leon, Nicaragua, and Chinese communities. ${ }^{17,38,48}$

This study also found a strongly significant association of undesired pregnancy, specifically by the husband, and violence during pregnancy. Considerable literature supports this association. ${ }^{10,13,14,16-20,38,49,50}$ One plausible reason for this association is that women who experience violence and undesired pregnancy live in an environment of patriarchy and male dominance. In addition, undesired pregnancy might be linked to forced intercourse, and women who reported physical violence had an increased rate of undesired pregnancy. ${ }^{18}$ However, Pallitto et al. ${ }^{16}$ found that unintended pregnancy in the United States was not always a potential risk of DV.

The results of this study showed that fear of husband or someone else in the house was associated with DV during the women's marital life and within the past year but not during pregnancy. This finding may be explained in that pregnant women in an abusive relationship would be more concerned with the progress and the outcome of their pregnancy than the perpetrators of violence. Another plausible explanation is that familial and extrafamilial ties and support for pregnant women change because of the pregnancy, resulting in a reduction of abuse or fear of husbands. It is likely, for example, in this context that the woman's mother or sister may come to stay with her during this period to assist with the pregnancy or with household chores. Husbands may be reluctant to inflict harm on their wives when there are immediate relatives in the house. Women when pregnant may also be able to increase or forge new contacts with others outside the home because of the pregnancy; for example, visits with healthcare providers increase during the prenatal period, providing additional contacts and support to the pregnant woman.

We also found that women had higher odds of abuse during their third and second trimesters compared with the first trimester. This was perhaps because at the third trimester, the pregnancy becomes harder to ignore, especially for husbands who did not want the pregnancy. It may also reflect the women's decreasing ability to perform her usual responsibilities.

Binary regression showed that within the last year and during pregnancy, younger age among pregnant women was associated with increased violence. This finding was consistent with other studies documenting associations between IPV and younger age. 9,13,17,19,26,29-31,51 Possible explanations could be that younger women are more vulnerable, dependent, lacking agency or autonomy, and more economically dependent on their husband or his family. Also, younger women are married to younger men, who might be more abusive and supportive of violence compared with older men in refugee contexts. ${ }^{1,26}$ Finally, it is possible that younger husbands and wives may be more emotionally unstable, leading to intense marital disagreements.

Parity ${ }^{10,13,17,19,42}$ and length of marriage $\mathrm{e}^{10,13,17,19,42}$ were found to be positively linked with violence in the literature but were not significant for abuse during lifetime and pregnancy in our study. Our findings were in line with those reported by Valladares et al. ${ }^{38}$ and Leung et al. ${ }^{51}$ These two variables were strongly related to the age of the woman, which may explain the lack of association. Previous literature showed that abuse during pregnancy was associated with low socioeconomic status $7,10,14,17,20,25,31,43,44$ and unemployment of the husband, $, 17,22,51,52$ but our study found no significant association between employment and DV. One plausible explanation of this finding is that the socioeconomic status of the Palestinian refugees in Lebanon has been generally low because of legal restrictions on participation in the formal labor market; Therefore, it may not be a determining factor in DV. Lebanese labor law restricts employment of Palestinian refugees to certain (low-skilled) occupations. Interestingly, living in a refugee camp was not significantly associated with DV during lifetime, within the past year, and during pregnancy. Although previous evidence pertaining to the prevalence of DV by camp residence among Palestinian refugees in Lebanon or elsewhere is lacking, refugee camps are generally more impoverished than other places. However, noncamp residents in our study generally live in low-income neighborhoods with living conditions fairly similar to those in the camps. It is perhaps the social, economic, and ideological characteristics of individuals and families rather than contextual factors (e.g., place of residence) that are associated with DV.

\section{Strengths and limitation of the study}

To our knowledge, this study was the first to address the prevalence and correlates of DV among pregnant women in the Arab countries. This study was also the first to use the AAS in detecting and identifying violence rates during pregnancy in a refugee context. Asking about violence during different periods and not only during pregnancy added strength to this study. In addition, this study highlighted 
some of the factors associated with violence against women, which will hopefully inform interventions to prevent this problem.

This study had several limitations. First, it took place in a single setting and may not be generalizable to other refugee populations in Lebanon or elsewhere. Domestic abuse remains hidden in Arab society, and women who are reluctant to disclose DV may need to be asked repeatedly over time. We know from previous studies conducted elsewhere that women are usually supportive of assessing for DV in a clinical setting, but such support varies by age and violence experience. ${ }^{53}$ The potential of underreporting could be expected on such a sensitive topic, especially among the young and those with a long history of abuse. Here, a cross-sectional survey was used to collect the data, limiting our ability to make causal statements about the findings from the study. Furthermore, the study suffers from the usual limitations of routine inquiries, including the potential for selectivity bias, as only women who used antenatal health services were included in the study. Our revision of the AAS instrument could be considered a limitation; the wording of the AAS instrument was modified following a pilot test and consultation with two practitioners familiar with the refugee context of the study. Another major limitation of this study was that no information about the husbands was collected; specifically, the study did not include all known factors associated with DV, such as the husband's alcohol and drug abuse. ${ }^{4}$

\section{Conclusions}

This study found that the majority of Palestinian refugee women are subjected to physical or emotional abuse at some point in their lives. Violence against pregnant women among Palestinian refugees in Lebanon was evident. Poor educational level, undesired pregnancy, and fear of husband or someone else in the house were possible factors associated with violence, although the direction of causality cannot be ascertained in a cross-sectional survey. Future studies on DV using a longitudinal study designs over longer periods of time are needed. ${ }^{54}$ Studies are also needed to document complications from IPV during pregnancy in this context. Little is known about the impact of abuse on children, including their health, behavior, and cognitive development, in countries of the Middle East region. Furthermore, studies of the dynamics of violence and abuse in the home using a variety of research methodology are lacking; hence, we know very little about the extent of mutual abuse by husbands and wives. Finally, existing studies have been limited to women respondents, neglecting the larger patriarchal context in which abuse occurs, including studies of contextual socioeconomic and political factors impacting violence as well as of the healthcare system.

This study sheds some light on some important aspects of clinical practice and policy development. Simple instruments, such as the AAS, with direct questioning on abuse may be effective in detecting cases of abuse; ${ }^{35}$ a recent randomized trial found no statistically significant difference in prevalence for different methods or instruments used in clinical settings. ${ }^{55}$ Practitioners, especially in developing countries, face many challenges in dealing with patients who experience DV, including the lack of clear practice guidelines. Healthcare providers may focus on providing psychosocial support, counseling, referral to appropriate agencies/professionals, and medical services to women in abusive relationships. When cases of abuse are detected, practitioners ought to protect patients first by inquiring about their safety and referring them to appropriate services. ${ }^{56}$

\section{Acknowledgments}

Special thanks to the United Nation Relief and Work Agency for Palestine Refugees for facilitating access to the women in the research site. We also thank the pregnant women for their involvement and cooperation during the course of this study.

\section{Disclosure Statement}

The authors have no conflicts of interest to report.

\section{References}

1. Khawaja M. Domestic violence in refugee camps in Jordan. Int J Gynaecol Obstet 2004;86:67-69.

2. Douki S, Nacef F, Belhadj A, Bouasker A, Ghachem R. Violence against women in Arab and Islamic countries. Arch Womens Ment Health 2003;6:165-171.

3. Robinson GE. International perspectives on violence against women-Introduction. Arch Womens Ment Health 2003;6: 155-156.

4. World Health Organization. World report on violence and health: Summary. Geneva. Available at www.who.int/ violence_injury_prevention/violence/world_report/en/full_en.pdf Accessed October 20, 2005.

5. Shadigian EM, Bauer ST. Screening for partner violence during pregnancy. Int J Gynaecol Obstet 2004;84:273-280.

6. Richardson J, Coid J, Petruckevitch A, Chung WS, Moorey S, Feder G. Identifying domestic violence: Cross-sectional study in primary care. BMJ 2002;324:1-6.

7. Martin SL, Mackie L, Kupper LL, Buescher PA, Moracco KE. Physical abuse of women before, during, and after pregnancy. JAMA 2001;285:1581-1584.

8. Waalen J, Goodwin MM, Spitz AM, Petersen R, Saltzman LE. Screening for intimate partner violence by health care providers: Barriers and interventions. Am J Prev Med 2000;19:230-237.

9. Anderson B, Marshak HH, Hebbeler DL. Identifying intimate partner violence at entry to prenatal care: Clustering routine clinical information. I Midwifery Womens Health 2002;47:353-359.

10. Nasir K, Hyder AA. Violence against pregnant women in developing countries: Review of evidence. Eur J Public Health 2003;13:105-107.

11. Fikree FF, Bhatti LI. Domestic violence and health of Pakistani women. Int J Gynaecol Obstet 1999;65:195-201.

12. Hegarty K, Roberts G. How common is a domestic violence against women? The definition of partner abuse in prevalence studies. Aust NZ J Public Health 1998;22:49-54.

13. Guo SF, Wu JL, Qu CY, Yan RY. Domestic abuse on women in China before, during, and after pregnancy. Chin Med J 2004;117:331-336.

14. Jasinski JL. Pregnancy and domestic violence: A review of the literature. Trauma Violence Abuse 2004;5:47-64. 
15. Johnson JK, Haider F, Ellis K, Hay DM, Lindow SW. The prevalence of domestic violence in pregnant women. $\mathrm{Br}$ J Obstet Gynaecol 2003;110:272-275.

16. Pallitto CC, Campbell JC, O'Campo P. Is intimate partner violence associated with unintended pregnancy? A review of the literature. Trauma Violence Abuse 2005;6:217-235.

17. Ying L. Does pregnancy provide immunity from intimate partner abuse among Hong Kong Chinese women? Soc Sci Med 2005;61:365-377.

18. Pallitto CC, O'Campo P. The relationship between intimate partner violence and unintended pregnancy in Colombia: An analysis of a national sample. Int Fam Plann Perspect 2004;30:165-173.

19. Dunn LL, Oths KS. Prenatal predictors of intimate partner abuse. J Obstet Gynecol Neonatal Nurs 2004;33:54-63.

20. Goodwin M, Gazmararian JA, Johnson $\mathrm{CH}$, Gilbert BC, Saltzman LE. Pregnancy intendedness and physical abuse around the time of pregnancy: Findings from the pregnancy risk assessment monitoring system, 1996-1997. Matern Child Health J 2000;4:85-92.

21. Bonomi AE, Anderson ML, Rivara FP, Thompson RS. Health outcomes in women with physical and sexual intimate partner violence. J Womens Health 2007;16:987-997.

22. Bacchus L, Mezey G, Bewley S. Domestic violence: Prevalence in pregnant women and associations with physical and psychological health. Eur J Obstet Gynecol Reprod Biol 2004;113:6-11.

23. Diop-Sidibé N, Campbell JC, Becker S. Domestic violence against women in Egypt: Wife-beating and health outcomes. Soc Sci Med 2006;62:1260-1277.

24. Yount K. Resources, family organization, and domestic violence against married women in Minya, Egypt. J Marriage Fam 2005;67:579-596.

25. Haj-Yahia MM, Ben-Arieh A. The incidence of Arab adolescents' exposure to violence in their families of origin and its socio-demographic correlates. Child Abuse Negl 2000;24: 1299-1315.

26. Khawaja M, Tewtel-Salem M. Agreement between husband and wife reports of domestic violence: Evidence from poor refugee communities in Lebanon. Int J Epidemiol 2004;33: 526-533.

27. Khawaja M, Barazi R. Prevalence of wife beating in Jordanian refugee camps: Reports by men and women. I Epidemiol Community Health 2005;59:840-841.

28. Hammoury N, Khawaja M. Screening for domestic violence during pregnancy in an antenatal clinic in Lebanon. Eur J Public Health 2007;17:505-506.

29. Koenig MA, Ahmad S, Hossain MB, Mozumder AB. Women's status and domestic violence in rural Bangladesh: Individualand community-level effects. Demography 2003;40:269-288.

30. Schuler SR, Hashemi SM, Riley AP, Akhter S. Credit programs, patriarchy and men's violence against women in rural Bangladesh. Soc Sci Med 1996;43:1729-1742.

31. Maziak W, Asfar T. Physical abuse in low income women in Aleppo, Syria. Health Care Women Int 2003;24:313-326.

32. Niaz U. Violence against women in south Asian countries. Arch Womens Ment Health 2003;6:173-184.

33. WHO. Ethical and safety recommendations for research on violence against women. Geneva: WHO, 1999.

34. Parker B, Ulrich Y, and the Nursing Research Consortium on Violence and Abuse. A protocol of safety: Research on abuse of women. Nursing Research 1990;39:248-250.

35. Sohal H, Eldridge H, Feder G. The sensitivity and specificity of four questions (HARK) to identify intimate partner vio- lence: A diagnostic accuracy study in general practice. PMC Fam Pract 2007;8:1-9.

36. Van Ommeren M. Validity issues in transcultural epidemiology. Br J Psychiatry 2003;182:376-378.

37. WHO. Gender and women's health. The WHO MutiCountry Study on Women's Health and Domestic Violence Against Women. Geneva: WHO, 2003.

38. Valladares E, Peãa R, Persson LÅ, Högbergc U. Violence against pregnant women: Prevalence and characteristics. A population-based study in Nicaragua. Br J Obstet Gynaecol 2005;112:1243-1248.

39. Nelson HD. Screening for domestic violence-Bridging the evidence gaps. Lancet 2004;364:22-23.

40. Ramsay J, Richardson J, Carter YH, Davidson LL, Feder G. Should health professionals screen women for domestic violence? Systematic review. BMJ 2002;325:1-13.

41. Nelson HD, Nygren P, McInerney Y, Klein J, U.S. Preventive Services Task Force. Screening women and elderly adults for family and intimate partner violence: A review of the evidence for the U.S. Preventive Services Task Force. Ann Intern Med 2004;140:387-396.

42. Bowen E, Heron J, Waylen A, Wolke D, ALSPAC Study Team. Domestic violence risk during and after pregnancy: Findings from a British longitudinal study. Br J Obset Gynaecol 2005;112:1083-1089.

43. Herzog S. Differential perceptions of the seriousness of male violence against female intimate partners among Jews and Arabs in Israel. J Interpers Violence 2004;19:891-900.

44. Haj-Yahia MM. The impact of wife abuse on marital relations as revealed by the second Palestinian national survey on violence against women. J Fam Psychol 2002;16: 273-285.

45. Peedicayil A, Sadowski LS, Jeyaseelan L, et al. Spousal physical violence against women during pregnancy. Br J Obstet Gynaecol 2004;111:682-687.

46. Sahin HA, Sahin HG. An unaddressed issue: Domestic violence and unplanned pregnancies among pregnant women in Turkey. Eur J Contracept Reprod Health Care 2003;8: 93-98.

47. Choi M, Harwood J. A hypothesized model of Korean women's responses to abuse. J Transcult Nurs 2004;15:207216.

48. Ezechi OC, Kalu BK, Ezechi LO, Nwokoro CA, Ndububa VI, Okeke GC. Prevalence and pattern of domestic violence against pregnant Nigeria women. J Obstet Gynecol 2004; 24:652-656.

49. Cokkinides VE, Coker AL, Sanderson M, Addy C, Bathea L. Physical violence during pregnancy: Maternal complications and birth outcomes. Obstet Gynecol 1999;93:661-666.

50. Cripe SM, Sanchez SE, Perales MT, Lam N, Garcia P, Williams MA. Associations between intimate partner physical and sexual violence with unintended pregnancy among pregnant women in Peru. Int J Gynaecol Obstet 2008;100: 104-108.

51. Leung WC, Leung TW, Lam YYJ, Ho PC. The prevalence of domestic violence against pregnant women in a Chinese community. Int J Gynaecol Obstet 1999;66:23-30.

52. Bacchus L, Mezey G, Bewley S, Harworth A. Prevalence of domestic violence when midwives routinely enquire in pregnancy. Br J Obstet Gynaecol 2004;111:441-445.

53. Zeitler MS, Paine AD, Breitbeit V, et al. Attitudes about intimate partner violence screening among an ethnically diverse sample of young women. J Adolesc Health 2006;39: 119.e1-119.e8. 
54. Coker AL, Flerx VC, Smith PH, Whitaker DJ, Fadden MK, Williams M. Intimate partner violence incidence and continuation in a primary care screening program. Am J Epidemiol 2007;165:821-827.

55. MacMillan HL, Wathen CN, Jamieson E, et al. Approaches to screening for intimate partner violence in health care settings. JAMA 2006;296:530-536.

56. Olive P. Care for emergency department patients who experienced domestic violence: A review of the evidence base. J Clin Nurs 2007;16:1736-1748.
Address reprint requests to: Dr. M. Khawaja Centre for Research on Population and Health American University of Beirut Bliss Street P.O. Box 11-0236

Beirut

Lebanon

E-mail: mk36@aub.edu.lb 
